\title{
What Do We See in the Discourse of Vision
}

\author{
CRAIG CALHOUN
}

\author{
University of North Carolina, Chapel Hill
}

From the cascading puns on visual language with which it opens, through its reports on the violent imagery of the Collège de Sociologie and the abstract antiocularcentrism of structuralists and poststructuralists, Martin Jay's book, Downcast Eyes: The Denigration of Vision in Twentieth-Century French Thought, is about writing as well as seeing, the discourse of vision more than visuality itself, and the centrality of vision as well as its denigration. It is a big book and a learned one, full of fascinating connections and informative recoveries of half-forgotten work. The book opens insights (one of many words that reading it makes difficult to use unself-consciously afterwards) into the work of an extremely wide range of late-nineteenth- and twentieth-century French thinkers. It refocuses our view of theories, old and new. It points to something pervasive that we may not have noticed adequately but ultimately fails to explain why this is so important.

Put another way, this is a work of intellectual history, focused on cultural theory, written with great theoretical acuity. Its intent seems to be theoretical and analytical, not only narrative, but its point is unclear. What Jay has done is to notice how issues of vision (including vision's violence and capacity to mislead) figure in an almost astonishing range of cultural analyses, theories, fictions, and related works. The issues of vision figure sometimes as tropes, sometimes as themes, sometimes as obsessions. They are occasionally linked by the influences that earlier works have on later ones and by the reaction formations so characteristic of French intellectual life. Jay identifies all he can, catalogues them, and uses them to help us grasp better the thoughts of these various thinkers, many well-known, a few obscure. But he also weaves them together, attempts to make of them a story of something happening in twentieth-century French thought, and here it is not clear whether there is any real unity. Did vision, or animosity to the centrality of vision to intellectual orientation, really shape the development of a coherent intellectual tradition in a basic way; or was it simply coincidentally prevalent throughout the last hundred years? It was clearly central to some thinkers, like Bataille, but for many others-denigrators as well as celebrants-it seems to have been as much a convenient figure for making points motivated elsewhere.

$0010-4175 / 96 / 21201-9908 \$ 7.50+.10$ C 1996 Society for Comparative Study of Society and History 
For all the implication that his narrative is leading somewhere, Jay winds up with a seven-and-a-half page conclusion that is the least satisfying, least persuasive part of his book. This takes nothing away from his scholarship, which is impressive as always, both in its range and its clarity of perception and exposition. It does raise questions both about his theme and object of attention and, in a somewhat more general way, about intellectual history itself.

In a sense, what Downcast Eyes charts is the great organizing tension between phenomenology/existentialism and structuralism/poststructuralism as forces in modern French thought. It shows that each builds on and reacts to positions taken before they were conjured into being as philosophical positions or "isms." To a lesser extent the book shows that positions in the debate were shaped by technology and other influences outside the near-solipsism of purely intellectual discourse, although this is never Jay's theme. His attention is never focused more than in passing on the social factors shaping intellectual currents or on the way in which intellectual history is embedded in a broader sort of history. He has written a very intellectualistic intellectual history, one that would be quite at home in the debates of small Parisian magazines. Indeed, one of the book's few stylistic flaws is the extent to which it depends on the reader's prior familiarity with most of the names and intellectual positions it addresses. Very French (though Jay first became famous as a historian of the Frankfurt School).

The book gets its orientations and sense of narrative direction from a vantage point in the present. It is Derrida and Irigaray, Levinas and Lyotard who provide the apparent dénouement. Indeed, there is considerable value in this. One of the problematic rhetorical tropes in much postmodernist discourse is the claim to radical novelty. Too many postmodernists (epigoni more than major thinkers) fool themselves in this regard. One of the important accomplishments of Jay's book is to show a rather considerable prehistory to one of the most important of postmodernist themes. We understand postmodernists and poststructuralists (or more properly, the range of internally heterogeneous discourses and positions lumped together under those labels when seen from a distance) better for seeing that their anti-visual tropes and themes have long been developing.

But did disenchantment with vision really point the way towards poststructuralism from the start? Or would we do better to see Downcast Eyes as a reading of how much later poststructuralist thinkers may have drawn from the late-nineteenth-century aesthetic crisis and, mostly indirectly from Bergson but more directly from Bataille and the Surrealists, Debord and the Lettrists, Lacan, Althusser, and even (though they would be loathe to admit it) Sartre and Merleau-Ponty. Focusing on their treatment of vision offers insight into the earlier thinkers, although not altogether on their own terms or with full attention to their own priorities. Jay's is a reading that derives its interest in 
anti-visual discourse from the centrality of that discourse for poststructuralist thinkers and then looks at others as precursors. Merleau-Ponty's interest in the relationship between visible and invisible was, for example, rooted in a very different intellectual outlook and project; one wonders whether it was really a meditation on the same theme or on a different issue using similar words.

Perhaps a comparison can make the point. Jay's earlier book, Marxism and Totality, traced the way in which a concept and a theme figured throughout an intellectual tradition. Successive chapters on different Marxist thinkersLukacs, Horkheimer, Adorno, Gramsci, and so forth-treated their different approaches to the notion of totality. Jay's analysis of those different approaches helped to make sense both of their specific theories and the development of Marxist thought. Downcast Eyes is organized rather similarly. It, too, uses a common theme to develop analyses of disparate bodies of work, and it, too, brings clarification and insight. But the Marxist tradition is much more clearly one intellectual tradition than those of late-nineteenth- and twentiethcentury French thought addressed in Downcast Eyes. And Jay offers more evidence (and we perhaps need less convincing) that totality figures in a basic way throughout the Marxist tradition, helps to distinguish the Marxist tradition from others, and was the object of the same kind of interest for different Marxist theories (even where they gave the idea of totality different definitions).

Jay is reasonable, then, in the modest phrasing of the first of his three conclusions: "A welter of overlapping attitudes, arguments, and assumptions shared by a large number of otherwise disparate thinkers has become apparent as never before" (p. 588). This becomes apparent because of Jay's analysis but also because recent poststructuralist debates have opened up the issue. This is not to suggest that he is wrong to see the continuity in the importance of vision and its denigration. Rather, it is to argue that his book would have benefited from a more explicit recognition of the retrospective constitution of its project to show how "the critique of ocularcentrism has helped fuel the concomitant weakening of faith among French intellectuals-and not them alone-in ... the modern project of enlightenment" (p. 589). A pornographic interest in vision and violence thus links Bataille and Breton back to Sade and has a continuity forward into some parts of the postmodernist discourse, but it took other aspects of poststructuralism to turn this challenge to Enlightenment into an intellectual interrogation of the modernist intellectual project. Jay's text is thematically integrated to the extent that it implicitly leads toward the French intellectuals' recent loss of faith in the modernist project, in ideas of sensory perception prior to writing or regimes of power, and in truth itself. But it is not clear that this is a "progressive" development nor that the various interrogations of vision by thinkers such as Merleau-Ponty and Sartre are best interpreted as steps on this path. They may have been, but to claim them as such requires an argument about connection, not only a demonstration of "overlap- 
ping attitudes, arguments, and assumptions." And in that connection, we can wonder even about the postmodernists. It remains unclear what status to ascribe to the attack on vision that Jay clearly shows runs through poststructuralist work. Is it metaphor or rhetorical device or motive or theme? Is it the point - or a way of getting some other point across?

In a sense, Jay's third conclusion really points to what makes his book interesting and useful: It charts a myriad of different ways in which "the antiocularcentric discourse has successfully posed substantial and troubling questions about the status of visuality in the dominant cultural traditions of the West" (p. 589). It is perhaps not the unity of the thinkers studied but their diversity that is most interesting. What is demonstrated in the end is not so much the progressive development of a valid or successful critique (after all, if the proof of the pudding is in the eating, much of this thought has proved indigestible, and neo-Kantians may yet carry the day). It is the very centrality of visuality itself that leaps from Jay's pages. What is demonstrated is that a wide range of thinkers felt compelled to respond to that centrality in the course of theorizing about contemporary life or taking up a critical stance on modernity. Jay (and the poststructuralists who underpin this aspect of his argument) may or may not be right that the West has been distinctively ocularcentric and that this is constitutive of Western intellectual traditions. Establishing this would require comparative analysis. But he is clearly right to discover an ubiquity of visuality in modern French discourse, and it may be this ubiquity of visuality that links the critiques more than the internal development of a single intellectual tradition.

I have remarked on the tension between phenomenology/existentialism and structuralism-poststructuralism that has been constitutive for so many debates. It may be that we are mislead by the polemical and reactive character of so much French writing. It may be that what is distinctive about French thought is the centrality of both phenomenology/existentialism and structuralism/poststructuralism and their serious and sustained interrelationship and that this crucially informs both the focus on the visual and its denigration. In other words, labels like postmodernism and poststructuralism may be misleading; even the sharp distinction of structuralism from phenomenology, surely accurate at one level, can be misleading at another. For the manner of focus on the relationship between the phenomenal and the constituted, the seen or spoken and the written, the habitually and the intentionally enacted is shaped by the presence of both traditions in the discourse. As Robert DeNoon Cumming once remarked in a class, some Germans make a project of dialectics, but it comes naturally for the French.

The attack on the primacy of the visual is an internal argument within this conflictual, dialectically constituted discourse. Or rather, several different attacks on the primacy of the visual have taken shape within this discourse, precisely because that primacy is never altogether shaken. As Jay writes, "the 
tenacious hold of ocularcentrism over Western culture . . was abetted by the oscillation among models of speculation, observation, and revelation" (p. 236). The phrase is neat, reminding us that theory, empiricism, and direct (including religious) intuition not only share Western culture but draw on its visual rhetoric. In this context, there can be a critique of the gaze and a call for reduction in the privileging of the eye; but an antivisual puritanism is as Quixotic as an attempt to speak or write without metaphors. It is akin to trying to do away entirely with representation, and as Derrida would suggest, such a desire is not only doomed but stems from the very metaphysics of presence that it seems to criticize, perpetuating the illusion that there might be a more direct access to knowledge.

Many of the most powerful "denigrations" of vision that Jay discusses turn out to be less one-sided rejections than ambivalent engagements. For the most part, moreover, they are engagements not with visuality as such but with modalities of vision: the gaze, the photograph, the spectacle. Thus, Sartre and later feminists in different ways chart the violence and pornography of the gaze (without ever suggesting quite that we should stop seeing); Barthes points to the false immediacy of the photograph ("an illogical conjunction between the here-now and the there-then," quoted by Jay, p. 443); and Debord analyzes the alienation implicit in the spectacle ("a social relation among people, mediated by images," quoted p. 427) without demonizing vision as such.

One of the things that a too-simplistic claim to a general denigration of vision would miss is the politics of the challenges posed by many of the thinkers that Jay discusses. In fact, Jay's actual accounts are not so simple, and they do not miss the politics (though his intellectualistic reading makes it hard to do justice to this side of the matter). He recognizes, for example, that the Lettrists, including the young Debord, were seeking to create "disruptive aesthetic situations with political implications" (p. 421). This might be a motto for what many French thinkers were doing in their critical engagements with various modalities of vision. They sought to disrupt stable rhetorics, modes of perception, and theories, nearly always with political intent. Understanding them fully may require an analysis of what was at stake politically and why this sort of intellectual activity could seem to be a mode of significant political action. This, of course, cannot be sorted out within a purely intellectual history. 